\title{
Predictor for cardiovascular risk in patients with type-2 diabetes mellitus
}

\author{
Md Azharuddin ${ }^{\mathrm{a}}$, Prem Kapur ${ }^{\mathrm{b}}$, Ritu Mishra ${ }^{\mathrm{c}}$, Shakir Saleem ${ }^{\mathrm{d}}$, Ashok Kumar Gupta ${ }^{\mathrm{e}}$, \\ Mohammad Adil ${ }^{\mathrm{c}}$, Manju Sharma ${ }^{\mathrm{a}, \mathrm{c}, *}$ \\ a Department of Pharmaceutical Medicine, Division of Pharmacology, School of Pharmaceutical Education and Research, Jamia Hamdard, New Delhi, India \\ ${ }^{\mathrm{b}}$ Department of Medicine, Hamdard Institute of Medical Sciences and Research, Jamia Hamdard, New Delhi, India \\ ${ }^{\mathrm{c}}$ Department of Pharmacology, School of Pharmaceutical Education and Research, Jamia Hamdard, New Delhi, India \\ ${ }^{\mathrm{d}}$ Department of Public Health, College of Health Science, Saudi Electronic University, Riyadh, Saudi Arabia \\ e Department of Pharmacy, School of Medical and Allied Sciences, Galgotia University, Greater Noida, India
}

\section{A R T I C L E I N F O}

\section{Keywords:}

Periostin

Cardiovascular risk

Acute coronary syndrome

Type 2 diabetes

\begin{abstract}
A B S T R A C T
Objective: Thelimited information available concerning the role of periostin associated with cardiovascular risk in patients with type 2 diabetes mellitus (T2DM). Therefore, this study aimed to find out the association between periostin level and inflammatory markers in patients with T2DM as well as in the acute coronary syndrome (ACS) patients.

Methods: This cross-sectional study randomly included a total of 210 participants, comprising T2DM $(\mathrm{n}=130)$, ACS $(n=40)$, and healthy group $(n=40)$. All anthropometric measures and biochemical parameters, periostin level, high sensitivity C-reactive protein (hs-CRP), and white blood cell (WBC) count were estimated. Pearson's correlation and linear multiple regression analysis was performed to assess the correlation and association between periostin level and other variables.

Results: Serum periostin levels were significantly higher among obese T2DM and ACS patients as compared to control. Positive correlation was found between serum periostin levels and waist circumference (WC), body mass index (BMI), fasting plasma glucose (FPG), postprandial glucose (PPG), glycated hemoglobin (HbA1c), triglyceride (TG), total cholesterol (TC), hs-CRP, WBC count, while negative correlation was observed with high-density lipoprotein $(H D L)(p<0.05)$. After adjustment, regression analysis showed that BMI, HbA1c, TC, HDL, WBC and hs-CRP were independently related to serum periostin levels $(\mathrm{p}<0.001)$.

Conclusion: The evidence of current study suggested that periostin levels were significantly higher among patients with ACS and obese T2DM, and it is significantly associated with lipid profile, anthropometric measures and inflammatory biomarkers. Our results revealed that periodic estimation of the circulating serum periostin could be a biomarker to predict the risk of developing cardiovascular complications in patients with T2DM. However, lacking of follow-up it further creates room for the future investigation.
\end{abstract}

\section{Introduction}

Patients suffering from type 2 diabetes mellitus (T2DM) have a two to three-fold risk of cardiovascular disease (CVD) compared to the general population. It has been found that $66.67 \%$ individuals suffering with T2DM have CVD risk factors ${ }^{1}$ and hence this comorbid condition remains a substantial public health burden with extensive clinical and socioeconomic impact. There are several factors have been recognized, including obesity, hypertension, hyperglycemia, proteinuria, sedentary lifestyle and dyslipidemia that contribute to the cardiovascular risk among T2DM patients. ${ }^{2,3}$
Obesity is strongly associated with inflammation and insulin insensitivity that leads to a lack of insulin action on the main insulin-sensitive tissues like adipose tissue, muscle, and liver. Insulin resistance induces both intra-arterial inflammation and extravascular stimuli, which consequently lead to the secretion of proinflammatory cytokines, that in turn promote the pathogenesis of CVD. ${ }^{4}$

The mechanism underlying the periostin and metabolic diseases is confirmed via the c-Jun N-terminal kinases (JNK)-mediated suppression of fatty acid oxidation in the liver. ${ }^{5}$

The fatty acid oxidation resulting from dyslipidemia may increase the level of triglycerides (TG) in the liver, while the hyperactivation of

\footnotetext{
* Corresponding author. Department of Pharmacology School of Pharmaceutical Education and Research Jamia Hamdard, New Delhi, 110062, India.

E-mail address: msharma@jamiahamdard.ac.in (M. Sharma).
} 
the JNK pathway contributes to the development of hepatic steatosis, obesity, and insulin resistance. , $^{6,7}$

A pre-clinical study, reported that alteration of periostin expression in the liver is associated with glucose and lipid metabolic disorders and obesity in an obese mouse model. ${ }^{5}$

Periostin is a member of fascilin family, expressed in various normal adult and fetal tissues, was initially identified in osteoblasts, originally cloned from a mouse osteoblast cell line. Periostin is a highly conserved extracellular matrix protein and actively contributes in the pathophysiology of tissue injury, fibrosis, tumor development, atherosclerosis, and inflammatory diseases. ${ }^{8}$ Periostin is a secreted protein expressed in cardiac fibroblasts and involved in cardiac dysfunction. ${ }^{9}$ Altered and overexpression of periostin was found in wide variety of diseases including cancer, lung disease, and CVD. ${ }^{8,10}$

Periostin may critically act as a scaffold and remodeling protein in inflammatory responses, obesity, and insulin resistance, that may reflect a novel molecular hint for the pathogenesis of T2DM and obesity. ${ }^{11}$

As TG have risen as the favored storage supplement for buffering against variations in energy demand and accessibility, dysregulated TG collection is firmly related to chronic inflammation, obesity and metabolic disorder. ${ }^{12,13}$ It may estimate that the relations between periostin, inflammation, and metabolic disorders are quite robust.

A study has found that Chinese patients with obesity and T2DM have significantly higher plasma periostin levels than healthy subjects and it is associated with TG metabolism, chronic inflammation, and insulin resistance. ${ }^{11}$ Insulin resistance has been identified as the main component of obesity and T2DM, both of which are related to systemic inflammation. ${ }^{14}$ However, in diabetic patients, periostin has been found to be associated with inflammatory markers interleukin-6 (IL-6) and C-reactive protein (CRP); these results have shown a possible mechanistic relationship between periostin and acute inflammation, and this may be a predictive and diagnostic marker for CVD in T2DM. ${ }^{15}$ Periostin may be playing a central role in the pathogenesis of heart failure (HF) and myocardial infraction (MI) among patients with diabetes, and the therapies targeting the periostin pathway may represent a novel treatment strategy. ${ }^{16}$

The increased periostin expression and related higher level of myocardial fibrosis was reported in patients with cardiac diseases such as MI, myocardial hypertrophy and dilated cardiomyopathy (DCM). ${ }^{17}$ Studies have also shown that periostin might play a potential role in the trafficking, activation, and cytokine release by leukocytes ${ }^{18,}, 19$

The unmet need of early detection and diagnosis of CV risk in people with T2DM is required to ensure adequate prevention to delay the diabetic complications. A few real-world data examined the relevancy of circulating periostin level and cardiovascular risk, and it remains unclear about to what extent periostin contributes to the development of CVD, especially in patients with T2DM. Furthermore, the incidence of T2DM in India is constantly rising along with cardiovascular risk. Hence, it is very important to identify risk of cardiovascular disease in diabetic patients to help decision or policy makers to ensure specific health care intervention.

Therefore, this study aimed to investigate the serum periostin as predictors of $\mathrm{CV}$ risk and find out its association with anthropometric measures and inflammatory markers in patients with T2DM as well as in the acute coronary syndrome (ACS) patients.

\section{Methods}

\subsection{Study design}

This cross-sectional study was conducted between May 2018 and September 2019 at Hakeem Abdul Hameed Centenary (HAHC) Hospital, Hamdard Institute of Medical Sciences \& Research (HIMSR), Jamia Hamdard, New Delhi, India. The study protocol was approved by Jamia Hamdard Institutional Ethics Committee (JHIEC), New Delhi, India. This study was carried out in full compliance with the Declaration of
Helsinki $^{20}$ (Brazil, October 2013) and written in accordance with the Strengthening the Reporting of Observational Studies in Epidemiology (STROBE) guidelines for reporting a cross-sectional study. ${ }^{21}$ Written informed consent was voluntarily obtained from all participants and they were assured of confidentiality and the anonymity of their identity.

\subsection{Sample size}

No study has assessed the association between periostin and inflammatory biomarkers in Indian T2DM patients. Therefore, the required sample size was calculated based on the results of pilot study, in pre- and post-design manner, involving 10 patients at $\alpha=5 \%$. It was determined that 130 patients were required to provide $95 \%$ statistical power of the study.

\subsection{Study population}

Patient selection was randomly carried out on the basis of predefined inclusion and exclusion criteria.

Only participants meeting all the following criteria were included in the study: (a) willingness to participate in the study by providing signed informed consent form; (b) 130 patients who had confirmed diagnosis of T2DM as per their medical records or having FPG (fasting plasma glucose) level $\geq 126 \mathrm{mg} / \mathrm{dl}$. (c) Forty each for ACS patients and healthy control group. ACS patients were diagnosed based on positive medical history (MI, angina pectoris and coronary artery bypass graft) and/or ECG changes.

In our study, we excluded the subjects who were pregnant, suffering with HIV, cancer, asthma, hepatic disease, and other infectious chronic disorders. Participants are also excluded who showed non-compliance with medications and taking medications that could affect their inflammatory status.

\subsection{Anthropometric measurements}

Anthropometric measures such as body weight, height, waist circumferences (WC), hip circumferences (HC), and blood pressure (BP) were measured in all subjects according to standard protocols.

WC were measured according to the WHO standard protocol (at the midpoint between the lower margin of the last palpable rib and the top of the iliac crest after the normal expiration). HC was measured at the widest diameter over the greater trochanters.

Body weight was measured to an accuracy of $0.1 \mathrm{~kg}$ and body mass index (BMI) computed as the weight per height squared (BMI = body mass $(\mathrm{kg}) /[\text { height }(\mathrm{m})]^{2}$ ). The waist-hip ratio (WHR) and waist to height ratio (WHtR) was calculated as the ratio of the waist circumferences and hip circumferences $(\mathrm{cm})$ and height $(\mathrm{cm})$.

Participants were classified into subgroups as normal weight, overweight $(23-24.9 \mathrm{~kg} / \mathrm{m} 2)$ and obese $(\geq 25 \mathrm{~kg} / \mathrm{m} 2)$ as per Consensus Guidelines for Asian Indians . ${ }^{22}$

BAI (body adiposity index) was proposed by Bergman et al. ${ }^{23}$ This is a composite index based on $\mathrm{HC}$ and height (BAI = [hip circumference $(\mathrm{cm}) /$ height $\left.(\mathrm{m})^{1.5}\right]-18$ ), and was measured with the intention that this index would provide a direct estimate of percentage (\%) body adiposity.

\subsection{Clinical and biochemical assessment}

The Patients were requested to be fasting overnight, venous blood samples $(5 \mathrm{ml})$ were collected and immediately transferred to ethylene diamine tetraacetate (EDTA) tube. The blood samples $(2 \mathrm{ml})$ were put into a dry tube for serum extraction, and serum was separated by centrifugation at $1000 \mathrm{~g}$ for $10-15 \mathrm{~min}$ at $4{ }^{\circ} \mathrm{C}$ and serum was stored at $-80^{\circ} \mathrm{C}$ until biomarker estimation. The remaining blood samples were used for the estimation of fasting plasma glucose (FPG) and all other biochemistry tests. FPG, PP (postprandial glucose) and lipid profile was measured by using fully automated Roche Cobas 6000 analyzer (Roche, 
Mannheim, Germany). Glycosylated hemoglobin (HbA1c) was estimated by using fully automated high-performance liquid chromatography using the BIORAD testing system. The complete blood count was determined using the automated analyzer. All biochemical parameters were carried out in the central pathology laboratory of HAHC hospital, Jamia Hamdard.

\subsection{Assessment of serum periostin and hs-CRP (high-sensitivity $C$ - Reactive protein) levels}

Serum periostin and hs-CRP levels were determined by the enzyme linked immunosorbent assays (ELISA) according to the manufacturer's instructions (Human ELISA kit, Elabscience Biotechnology Inc. USA). The coefficient of variation was $<10 \%$.

\subsection{Statistical analysis}

All data were expressed as mean \pm standard deviation (SD), and categorical variables are expressed as frequencies. Student's $t$-test was used to test the significant differences in the continuous variables. ANOVA test was used to compare the differences among groups.

Pearson's correlation analysis was performed in order to assess the association between the serum periostin levels and other variables. Partial correlation analysis was performed after controlling for variables including age, sex, and BMI.

Multiple linear regression analysis was performed to find out the relationship between serum periostin levels as dependent or outcome variable and other variables as independent.

The area under the receiver operating characteristic (ROC) curve was plotted to test the index in the diagnosis. All the study data were analyzed using the Statistical Package for Social Sciences; SPSS software version 20.0 for Windows (SPSS Inc., Chicago, IL, USA). Values of $\mathrm{p}<$ 0.05 was considered statistically significant.

\section{Results}

A total of 210 participants were studied, among these 130 were T2DM patients and 40 each of healthy control and ACS patients. The anthropometric, clinical, and biochemical parameters of the study participants are described in Table 1. Among the three groups, there were no significant differences in age, diastolic blood pressure (DBP), weight, BMI, WC, HC, WHR, total cholesterol (TC), TG, low density lipoprotein (LDL). However, height, systolic blood pressure (SBP), FPG, HbA1c, high density lipoprotein (HDL), white blood cell (WBC) count, hs-CRP and periostin were significantly different among the three groups $(\mathrm{p}<0.05$, $\mathrm{p}<0.001$ ).

Compared with the healthy controls, the T2DM group had significantly higher levels of SBP, BMI, WC, BAI, FPG, HbA1c, WBC count, hsCRP and periostin ( $p<0.05$ or 0.01 ), whereas the levels of HDL were significantly lower in the T2DM group than in the control group ( $\mathrm{p}<$ 0.001). Compared with the control group, the levels of SBP, DBP, HC, TC, very low-density lipoprotein (VLDL), WBC count, hs-CRP and periostin were significantly higher in the ACS patients ( $p<0.05$ or 0.01 ), while the levels of HDL were significantly lower in the ACS patients $(\mathrm{p}<$ 0.001).

Table 2 shows the comparison of clinical and biochemical parameters of study participants grouped according to BMI. Compared with the T2DM-normal weight subgroup, SBP, height, weight, BMI, WC, HC, WHtR, BAI, HbA1c, TG, VLDL, WBC count, and periostin were significantly higher in T2DM-obese. The height, weight, BMI, WC, HC, WHR, WHtR, BAI, and periostin were found significantly differ among three groups ( $\mathrm{p}<0.05$ or 0.01 ).

\subsection{Serum periostin levels in different groups}

There were no significant differences in serum periostin levels were
Table 1

Clinical and biochemical parameters in study groups.

\begin{tabular}{|c|c|c|c|c|}
\hline Variables & $\begin{array}{l}\text { Control (n } \\
=40)\end{array}$ & $\begin{array}{l}\text { T2DM }(\mathrm{n}= \\
130)\end{array}$ & $\operatorname{ACS}(n=40)$ & $P$ value \\
\hline Age (years) & $\begin{array}{l}49.65 \pm \\
6.47\end{array}$ & $52.42 \pm 10.54$ & $\begin{array}{l}54.37 \pm \\
12.28^{\mathrm{b} *}\end{array}$ & 0.118 \\
\hline $\begin{array}{l}\text { Gender (male/ } \\
\text { female) }\end{array}$ & $28 / 12$ & $53 / 77$ & $19 / 21$ & - \\
\hline $\begin{array}{l}\text { Systolic BP } \\
\text { (mmHg) }\end{array}$ & $\begin{array}{l}123.47 \pm \\
6.48\end{array}$ & $\begin{array}{l}132.24 \pm \\
14.95^{\mathrm{a} * *}\end{array}$ & $\begin{array}{l}140.70 \pm \\
23.09^{\mathrm{b}_{* *}}\end{array}$ & $0.0001 * *$ \\
\hline $\begin{array}{l}\text { Diastolic BP } \\
\text { (mmHg) }\end{array}$ & $\begin{array}{l}80.12 \pm \\
7.80\end{array}$ & $82.07 \pm 15.23$ & $\begin{array}{l}85.62 \pm \\
15.51^{\mathrm{b} *}\end{array}$ & 0.222 \\
\hline Height (cm) & $\begin{array}{l}162.65 \pm \\
9.42\end{array}$ & $\begin{array}{l}158.02 \pm \\
8.038^{\mathrm{a} *}\end{array}$ & $159.62 \pm 11.08$ & $0.017^{*}$ \\
\hline Weight (kg) & $\begin{array}{l}64.20 \pm \\
11.36\end{array}$ & $65.66 \pm 12.29$ & $68.52 \pm 13.85$ & 0.278 \\
\hline BMI $\left(\mathrm{kg} / \mathrm{m}^{2}\right)$ & $\begin{array}{l}24.38 \pm \\
4.41\end{array}$ & $26.38 \pm 5.17^{\mathrm{a} *}$ & $26.20 \pm 6.04$ & 0.104 \\
\hline WC $(\mathrm{cm})$ & $\begin{array}{l}87.89 \pm \\
10.19\end{array}$ & $\begin{array}{l}91.84 \pm \\
11.19^{\mathrm{a} *}\end{array}$ & $91.32 \pm 17.28$ & 0.316 \\
\hline $\mathrm{HC}(\mathrm{cm})$ & $\begin{array}{l}89.57 \pm \\
9.83\end{array}$ & $92.43 \pm 12.80$ & $\begin{array}{l}94.65 \pm \\
10.00^{\mathrm{b} *}\end{array}$ & 0.156 \\
\hline WHR & $0.98 \pm 0.08$ & $0.99 \pm 0.08$ & $0.96 \pm 0.15$ & 0.393 \\
\hline WHtR & $0.54 \pm 0.07$ & $0.57 \pm 0.07$ & $0.56 \pm 0.13$ & 0.079 \\
\hline BAI & $\begin{array}{l}25.47 \pm \\
6.31\end{array}$ & $28.78 \pm 7.65^{\mathrm{a} *}$ & $28.16 \pm 10.08$ & 0.072 \\
\hline FPG (mg/dl) & $\begin{array}{l}92.97 \pm \\
8.95\end{array}$ & $\begin{array}{l}163.50 \pm \\
65.28^{\mathrm{a} * *}\end{array}$ & $95.45 \pm 11.18$ & $0.0001 * *$ \\
\hline $\mathrm{PP}$ (mg/dl) & - & $238.67 \pm 83.0$ & - & - \\
\hline HbA1c (\%) & $5.40 \pm 0.65$ & $8.64 \pm 2.49^{a * *}$ & $5.75 \pm 0.41^{\mathrm{b} *}$ & $0.0001^{* *}$ \\
\hline $\begin{array}{l}\text { Duration of } \\
\text { diabetes } \\
\text { (years) }\end{array}$ & - & $5.75 \pm 4.89$ & - & \\
\hline TC (mg/dl) & $\begin{array}{l}155.70 \pm \\
37.02\end{array}$ & $\begin{array}{l}165.53 \pm \\
37.86\end{array}$ & $\begin{array}{l}171.35 \pm \\
32.21^{\mathrm{b} *}\end{array}$ & 0.156 \\
\hline TG (mg/dl) & $\begin{array}{l}127.23 \pm \\
54.63\end{array}$ & $\begin{array}{l}137.27 \pm \\
63.78\end{array}$ & $140.13 \pm 46.48$ & 0.569 \\
\hline HDL (mg/dl) & $\begin{array}{l}52.59 \pm \\
10.83\end{array}$ & $\begin{array}{l}48.42 \pm \\
13.26^{\mathrm{a} *}\end{array}$ & $\begin{array}{l}38.26 \pm \\
5.51^{\mathrm{b} * *}\end{array}$ & $0.0001 * *$ \\
\hline LDL (mg/dl) & $\begin{array}{l}109.67 \pm \\
29.28\end{array}$ & $\begin{array}{l}114.16 \pm \\
31.41\end{array}$ & $118.91 \pm 22.27$ & 0.376 \\
\hline VLDL (mg/dl) & $\begin{array}{l}25.40 \pm \\
10.84\end{array}$ & $28.24 \pm 16.11$ & $\begin{array}{l}31.55 \pm \\
12.41^{\mathrm{b} *}\end{array}$ & 0.171 \\
\hline $\begin{array}{l}\text { WBC count } \\
\text { (cells/cumm) }\end{array}$ & $\begin{array}{l}7609.00 \pm \\
1046.24\end{array}$ & $\begin{array}{l}8600.64 \pm \\
2080.33^{\mathrm{a} * *}\end{array}$ & $\begin{array}{l}8969.00 \pm \\
2112.88^{\mathrm{b} * *}\end{array}$ & $0.004 *$ \\
\hline $\begin{array}{l}\text { Periostin (ng/ } \\
\text { mL) }\end{array}$ & $\begin{array}{l}11.75 \pm \\
2.98\end{array}$ & $\begin{array}{l}26.89 \pm \\
13.63^{\mathrm{a} * *}\end{array}$ & $\begin{array}{l}123.05 \pm \\
34.98^{\mathrm{b} * *}\end{array}$ & $0.0001^{* *}$ \\
\hline hs-CRP (pg/mL) & $\begin{array}{l}26.65 \pm \\
12.81\end{array}$ & $\begin{array}{l}310.52 \pm \\
257.23^{\mathrm{a} * *}\end{array}$ & $\begin{array}{l}557.37 \pm \\
305.54^{\mathrm{b} * *}\end{array}$ & $0.0001 * *$ \\
\hline
\end{tabular}

Abbreviation: T2DM: type 2 diabetes mellitus; ACS: acute coronary syndrome; BP: blood pressure; BMI: body mass index; WC: waist circumference; HC; hip circumference; WHR: Waist to hip ratio; WHtR: Waist to height ratio; BAI: boy adiposity index; FPG: fasting plasma glucose; PP: postprandial glucose; HbA1c: glycated haemoglobin; TC: total cholesterol; TG: triglycerides; HDL: high density lipoprotein; LDL: low density lipoprotein; VLDL: very low density lipoprotein; WBC: white blood cell; hs-CRP: high-sensitivity C-Reactive Protein.

$* \mathrm{p}<0.05$.

$* * \mathrm{p}<0.01$.

a Control versus diabetic patients.

b Control versus ACS patients.

observed between male and female group $(24.48 \pm 12.38 \mathrm{ng} / \mathrm{mL}$ versus $28.55 \pm 14.27 \mathrm{ng} / \mathrm{mL}, \mathrm{p}=0.095$ ) in T2DM patients (Fig. 1.).

Compared with the T2DM-normal weight group, the T2DM overweight and obese group had significantly higher serum periostin levels $(19.85 \pm 10.54 \mathrm{ng} / \mathrm{mL}$ versus $25.74 \pm 13.04 \mathrm{ng} / \mathrm{mL}$ and $29.79 \pm 13.94$ $\mathrm{ng} / \mathrm{mL}, \mathrm{p}<0.05$; Fig. 2.).

\subsection{Pearson's and partial correlation analysis}

Table 3 showed the correlation between serum periostin levels and biochemical parametrs and inflammatory markers among ACS patients. Pearson's correlation analysis showed positive correlation between serum periostin levels and BMI, SBP, HC, BAI, VLDL and inflammatory 
Table 2

Comparison of clinical and biochemical parameters of T2DM patients categorized on the basis of BMI.

\begin{tabular}{|c|c|c|c|c|}
\hline Variables & $\begin{array}{l}\text { T2DM-Normal } \\
\text { weight }(\mathrm{n}= \\
\text { 29) }\end{array}$ & $\begin{array}{l}\text { T2DM- } \\
\text { Overweight (n } \\
=22)\end{array}$ & $\begin{array}{l}\text { T2DM-Obese } \\
(\mathrm{n}=79)\end{array}$ & $P$ value \\
\hline Age (years) & $52.96 \pm 8.22$ & $52.18 \pm 10.07$ & $\begin{array}{l}52.29 \pm \\
11.50\end{array}$ & 0.952 \\
\hline $\begin{array}{c}\text { Systolic BP } \\
(\mathrm{mmHg})\end{array}$ & $\begin{array}{l}126.44 \pm \\
12.33\end{array}$ & $\begin{array}{l}134.13 \pm \\
13.37^{\alpha *}\end{array}$ & $\begin{array}{l}133.84 \pm \\
15.83^{\mathrm{b} *}\end{array}$ & 0.059 \\
\hline $\begin{array}{c}\text { Diastolic BP } \\
\text { (mmHg) }\end{array}$ & $82.51 \pm 20.49$ & $81.50 \pm 9.92$ & $\begin{array}{l}82.07 \pm \\
14.36\end{array}$ & 0.973 \\
\hline Height $(\mathrm{cm})$ & $160.44 \pm 7.07$ & $160.86 \pm 9.47$ & $\begin{array}{l}156.34 \pm \\
7.57^{\mathrm{b} *}\end{array}$ & $0.011^{*}$ \\
\hline Weight (kg) & $52.55 \pm 6.72$ & $62.27 \pm 6.63^{\mathrm{a} * *}$ & $\begin{array}{l}71.41 \pm \\
11.00^{\mathrm{b} * *}\end{array}$ & $0.0001^{* *}$ \\
\hline BMI (kg/m2) & $20.37 \pm 1.80$ & $24.02 \pm 0.55^{\mathrm{a} * *}$ & $\begin{array}{l}29.24 \pm \\
4.44^{\mathrm{b} * *}\end{array}$ & $0.0001^{* *}$ \\
\hline WC $(\mathrm{cm})$ & $84.31 \pm 8.29$ & $90.05 \pm 10.17^{a *}$ & $\begin{array}{l}94.12 \pm \\
11.31^{\mathrm{b} * *}\end{array}$ & $0.0001^{* *}$ \\
\hline $\mathrm{HC}(\mathrm{cm})$ & $87.20 \pm 15.08$ & $89.58 \pm 8.42$ & $\begin{array}{l}95.15 \pm \\
12.27^{\mathrm{b} *}\end{array}$ & $0.008^{*}$ \\
\hline WHR & $0.98 \pm 0.11$ & $1.00 \pm 0.05$ & $0.99 \pm 0.07$ & 0.604 \\
\hline WHtR & $0.52 \pm 0.04$ & $0.56 \pm 0.06^{\mathrm{a} *}$ & $\begin{array}{l}0.60 \pm \\
0.07^{\mathrm{b} * *}\end{array}$ & $0.0001^{* *}$ \\
\hline BAI & $25.00 \pm 7.73$ & $26.05 \pm 4.65$ & $\begin{array}{l}30.93 \pm \\
7.57^{\mathrm{b} * *}\end{array}$ & $0.0001 * *$ \\
\hline FPG (mg/dl) & $\begin{array}{l}144.98 \pm \\
55.90\end{array}$ & $165.63 \pm 58.16$ & $\begin{array}{l}167.87 \pm \\
69.81\end{array}$ & 0.343 \\
\hline $\mathrm{PP}$ (mg/dl) & $\begin{array}{l}218.80 \pm \\
88.61\end{array}$ & $241.30 \pm 82.85$ & $\begin{array}{l}246.59 \pm \\
79.60\end{array}$ & 0.452 \\
\hline HbA1c (\%) & $7.89 \pm 2.67$ & $8.69 \pm 2.46$ & $\begin{array}{l}9.10 \pm \\
2.39^{\mathrm{b} *}\end{array}$ & 0.081 \\
\hline $\begin{array}{l}\text { Duration of } \\
\text { diabetes } \\
\text { (years) }\end{array}$ & $5.72 \pm 6.87$ & $4.47 \pm 2.49$ & $6.11 \pm 4.51$ & 0.383 \\
\hline $\mathrm{TC}(\mathrm{mg} / \mathrm{dl})$ & $\begin{array}{l}158.27 \pm \\
30.02\end{array}$ & $167.11 \pm 40.79$ & $\begin{array}{l}169.40 \pm \\
36.42\end{array}$ & 0.491 \\
\hline $\mathrm{TG}(\mathrm{mg} / \mathrm{dl})$ & $\begin{array}{l}115.15 \pm \\
46.00\end{array}$ & $141.22 \pm 59.32$ & $\begin{array}{l}152.22 \pm \\
90.18^{\mathrm{b} * *}\end{array}$ & 0.081 \\
\hline HDL (mg/dl) & $49.09 \pm 13.66$ & $48.10 \pm 12.35$ & $\begin{array}{l}48.27 \pm \\
15.72\end{array}$ & 0.962 \\
\hline LDL (mg/dl) & $\begin{array}{l}114.79 \pm \\
33.50\end{array}$ & $110.90 \pm 33.27$ & $\begin{array}{l}114.84 \pm \\
30.45\end{array}$ & 0.869 \\
\hline VLDL (mg/dl) & $23.02 \pm 9.20$ & $30.39 \pm 18.06^{\mathrm{a} *}$ & $\begin{array}{l}29.55 \pm \\
17.26^{\mathrm{b} *}\end{array}$ & 0.138 \\
\hline $\begin{array}{l}\text { WBC count } \\
\text { (cells/ } \\
\text { cumm) }\end{array}$ & $\begin{array}{l}8062.33 \pm \\
2477.62\end{array}$ & $\begin{array}{l}8167.58 \pm \\
2115.64\end{array}$ & $\begin{array}{l}8909.51 \pm \\
1910.49^{\mathrm{b} *}\end{array}$ & 0.138 \\
\hline $\begin{array}{l}\text { Periostin (ng/ } \\
\text { mL) }\end{array}$ & $19.85 \pm 10.54$ & $25.74 \pm 13.04^{a *}$ & $\begin{array}{l}29.79 \pm \\
13.94^{\mathrm{b} * *}\end{array}$ & $0.003^{*}$ \\
\hline $\begin{array}{l}\text { hs-CRP (pg/ } \\
\text { mL) }\end{array}$ & $\begin{array}{l}264.42 \pm \\
251.13\end{array}$ & $\begin{array}{l}294.69 \pm \\
252.23\end{array}$ & $\begin{array}{l}331.85 \pm \\
261.42\end{array}$ & 0.462 \\
\hline
\end{tabular}

Abbreviation: T2DM: type 2 diabetes mellitus; BMI: body mass index; ACS: acute coronary syndrome; BP: blood pressure; WC: waist circumference; HC; hip circumference; WHR: Waist to hip ratio; WHtR: Waist to height ratio; BAI: boy adiposity index; FPG: fasting plasma glucose; PP: postprandial glucose; HbA1c: glycated haemoglobin; TC: total cholesterol; TG: triglycerides; HDL: high density lipoprotein; LDL: low density lipoprotein; VLDL: very low density lipoprotein; WBC: white blood cell; hs-CRP: high-sensitivity C-Reactive Protein.

$* \mathrm{p}<0.05$.

$* * \mathrm{p}<0.01$.

a T2DM-Normal weight versus T2DM-Overweight.

b T2DM-Normal weight versus T2DM-Obese.

marker; WBC count and hs-CRP ( $\mathrm{p}<0.05)$ (Table 3.), whereas the HDL levels were negatively associated $(\mathrm{p}<0.05)$.

Among the T2DM patients, Pearson correlation analysis showed positive correlation between serum periostin levels and BMI, WC, WHR, BAI, FPG, PP, HBA1c, TC, TG, WBC count and hs-CRP $(\mathrm{p}<0.05)$ (Table 4.), while HDL has shown negative correlation ( $p<0.05)$. The partial correlation was conducted after controlling the age, sex BMI, weight, \& duration of diabetes and it still remained significant ( $\mathrm{p}<$ 0.05).

\subsection{Multiple linear regression analysis}

A Multiple regression analysis performed to find out the relationship between serum periostin levels and biochemical parameters and inflammatory marker, are presented in Table 5. Regression analysis showed that BMI, HbA1c, TC, HDL, WBC count and hs-CRP were independently related to serum periostin levels $(p<0.001)$.

\subsection{ROC curve analysis of serum periostin}

ROC curve was plotted to understand the sensitivity and specificity of periostin biomarkers for cardiovascular risk. Levels of circulating periostin were compared among T2DM patients with healthy subjects and ACS patients. The ROC analysis of periostin (Fig. 3.) yielded an AUC of 0.745 (95\% CI: 0.67, 0.81; p < 0.0001). The differences were statistically significant which suggested that biomarkers can be utilized in the early detection of cardiovascular risk.

\section{Discussions}

This cross-sectional study linked the association between serum periostin and glucose parameters, anthropometric measures and inflammatory markers in patients with T2DM. Additionally, the circulating serum periostin levels in the ACS patients was estimated and its association with lipid parameters, inflammatory markers and body fat parameters was assessed.

A study has shown that inflammation is highly reactive and involved in more active inflammatory response among ACS patients. ${ }^{24}$ As we found that body fat parameters, inflammatory markers and lipid parameters are significantly higher in ACS patients as compared against control subject. The findings of this study reported that TC, TG, LDL, and hs-CRP were higher in the ACS patients, while HDL was significantly lower than the control group which was linear to the previous reports. The results indicated the occurrence of severe coronary artery injury in ACS patients. ${ }^{25}$ hs-CRP is the well-established serum inflammatory marker, which reflects the process of atherosclerotic plaque. ${ }^{26}$

ACS is associated with rupture of an atherosclerotic plaque and partial or complete thrombosis of the infarct-related artery. ${ }^{27}$ Ruptured plaques contribute to thrombus formation via inflammatory mechanisms, with the help of activated and inactivated platelets and platelet-leukocyte adhesions, that leads to the development of ACS. ${ }^{28-30}$ In the presented study, serum periostin levels were significantly associated with inflammatory markers in patients with ACS. Therefore, inflammatory markers associated periostin level could be predictor for risk stratification of ACS patients.

Similarly, this study found that overweight and obese Indian subjects with T2DM have significantly higher serum periostin levels than healthy control and that periostin is strongly associated with TC, TG, BAI and inflammatory markers; WBC counts and hs-CRP. In line with the presented report, a recent study carried out in Chinese subjects with T2DM, stated that obese patients with T2DM have significantly higher plasma periostin levels than healthy controls and that periostin is strongly associated with TG, chronic inflammation, and insulin resistance. ${ }^{11}$ In addition, this study reported significantly higher levels of WBC count in obese T2DM compared to healthy control. This may be because, obesity and insulin resistance are associated with adipocytokines and inflammatory markers, as leukocyte is one of the markers of inflammation. ${ }^{31}$ Results from a study reveal that WBC levels above 6900 cells/cumm were associated with a 2.17 -fold increase $(95 \% \mathrm{CI}=1.18-3.97)$ in the risk for $\mathrm{CAD}$ as compared with men in WBC count $\leq 5400$ cells/cumm. WBC count may be considered as independent risk factor for CAD in young adults. ${ }^{32}$

As per the reports, both animal and human models reveal that periostin is involved in the pathophysiology of metabolic diseases via the JNK-mediated suppression of fatty acid oxidation in the liver. ${ }^{5}$ This study found that serum periostin levels were positively correlated with 


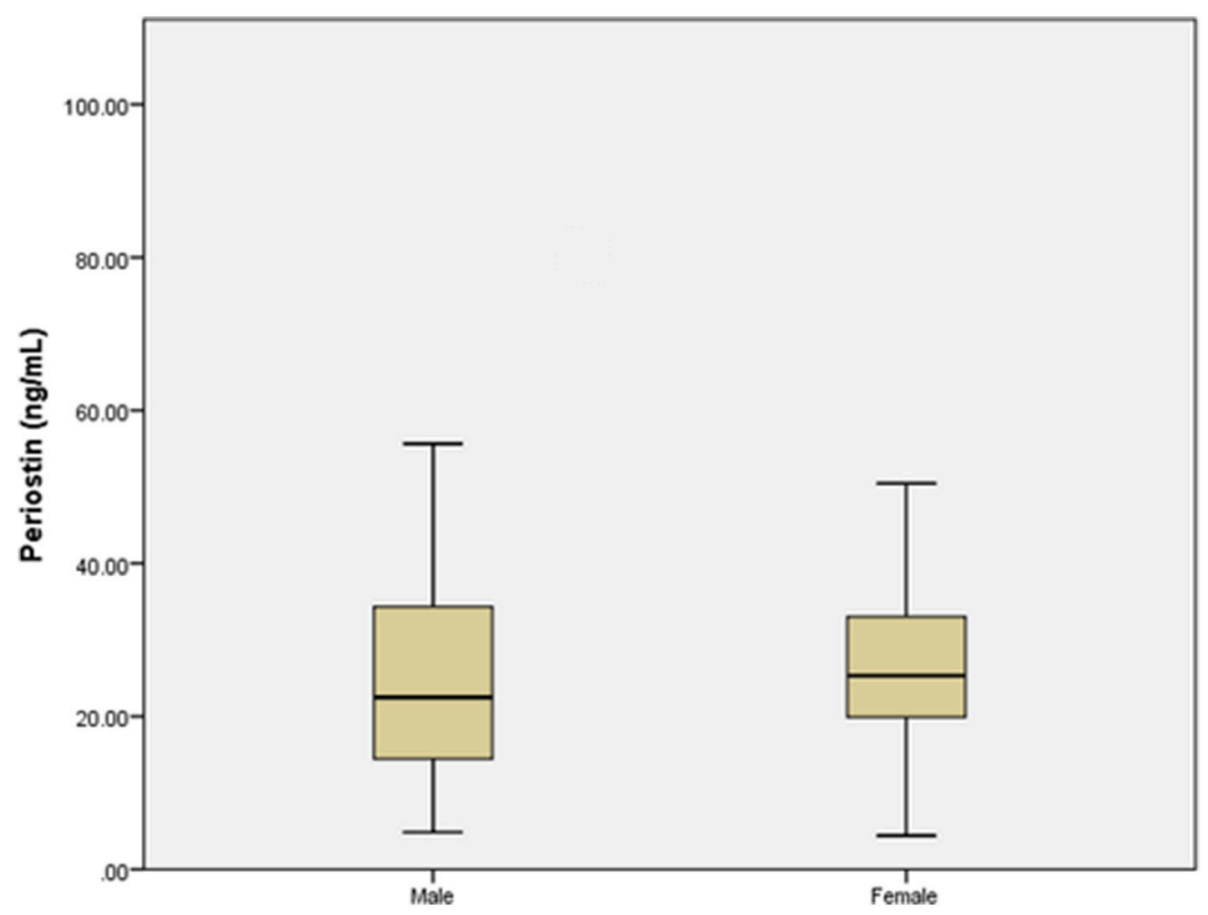

Fig. 1. Serum periostin levels in the male and female group. The data are presented as the mean \pm SD.

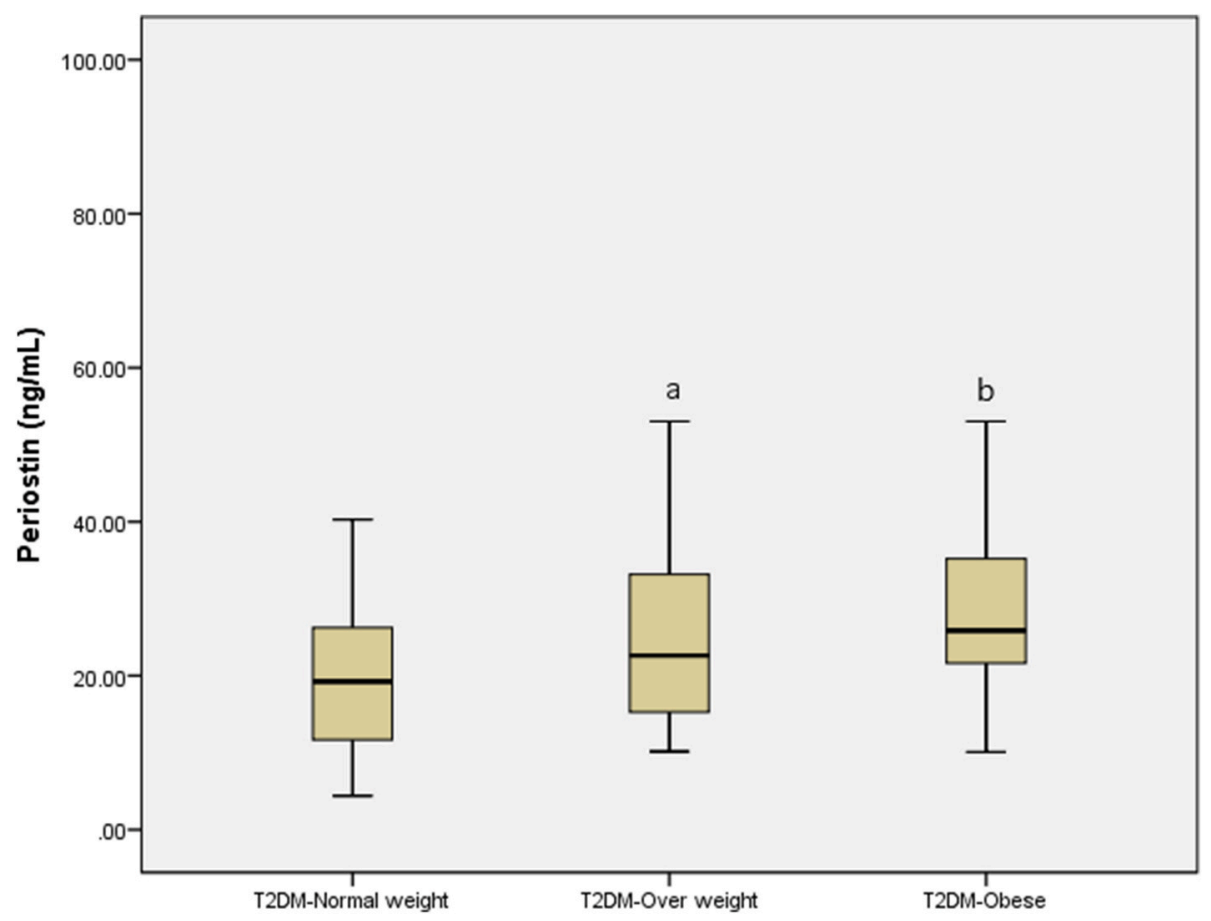

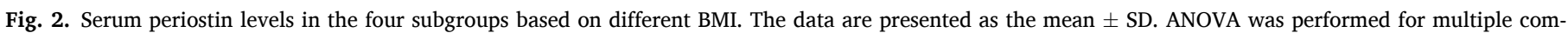
parisons. a: $\mathrm{p}<0.05$ T2DM-Normal weight versus T2DM-Over weight. b: $\mathrm{p}<0.01$ T2DM-Normal weight versus T2DM-Obese.

TG and TC. However, a negatively correlation was noticed with HDL. After controlling age, sex, BMI, weight, \& duration of diabetes, a positive correlation was found for WBC counts, hs-CRP, TG and TC but HDL wasnegatively correlated. The outcomes of this study were also consistent to a report which documented that plasma periostin levels were positively correlated with TG and TC and negatively correlated with HDL-C. ${ }^{1}$

Therefore, BMI, lipid parameters and inflammatory markers were found to be independent risk factors influencing serum periostin levels in patients with T2DM. This finding substantiated that systemic inflammation is considered as a link between obesity, diabetes and cardiovascular diseases. ${ }^{33}$ Previous studies have shown that elevated levels of hs-CRP is associated with obesity, diabetes, and CVD. ${ }^{34,35}$ The higher levels of hs-CRP in this study were found in obese T2DM patients and serum periostin levels were positively correlated with inflammatory markers among T2DM patients.

We found that periostin levels were also positively correlated with the body fat parameters like BMI, WC, WHR and BAI and with glucose 
Table 3

Pearson correlation of variables associated with serum periostin in ACS patients.

\begin{tabular}{lll}
\hline Variables & $\mathrm{r}$ & P value \\
\hline Age (years) & -0.070 & 0.666 \\
BMI (kg/m2) & 0.804 & $0.041^{*}$ \\
Systolic BP (mmHg) & 0.876 & $0.026^{*}$ \\
Diastolic BP (mmHg) & 0.099 & 0.543 \\
WC (cm) & 0.213 & 0.187 \\
HC (cm) & 0.390 & $0.043^{*}$ \\
WHR & 0.203 & 0.521 \\
BAI & 0.662 & $0.041^{*}$ \\
TC (mg/dl) & 0.101 & 0.536 \\
TG (mg/dl) & 0.214 & 0.185 \\
HDL (mg/dl) & -0.172 & $0.028^{*}$ \\
LDL (mg/dl) & 0.018 & 0.910 \\
VLDL (mg/dl) & 0.336 & $0.034^{*}$ \\
WBC count (cells/cumm) & 0.344 & $0.030^{*}$ \\
hs-CRP (pg/mL) & 0.468 & $0.008^{*}$
\end{tabular}

Abbreviation: ACS: acute coronary syndrome; BMI: body mass index; BP: blood pressure; WC: waist circumference; HC; hip circumference; WHR: Waist to hip ratio; BAI: boy adiposity index; TC: total cholesterol; TG: triglycerides; HDL: high density lipoprotein; LDL: low density lipoprotein; VLDL: very low density lipoprotein; WBC: white blood cell; hs-CRP: high-sensitivity C-Reactive Protein. r, Correlation coefficient.

*, Statistically significant correlation $(\mathrm{p}<0.05)$.

Table 4

Pearson correlation and partial correlation of variables associated with serum periostin in T2DM patients.

\begin{tabular}{|c|c|c|c|c|}
\hline \multirow[b]{2}{*}{ Variables } & \multicolumn{2}{|c|}{ Pearson correlation } & \multicolumn{2}{|c|}{ Partial Correlation } \\
\hline & $\mathrm{r}$ & $P$ value & & $P$ value \\
\hline Age (years) & -0.054 & 0.543 & - & - \\
\hline BMI (kg/m2) & 0.244 & $0.005^{*}$ & - & - \\
\hline Weight & 0.188 & $0.032 *$ & - & - \\
\hline Systolic BP (mmHg) & 0.000 & 0.997 & 0.059 & 0.517 \\
\hline Diastolic BP (mmHg) & 0.061 & 0.493 & 0.095 & 0.296 \\
\hline $\mathrm{WC}(\mathrm{cm})$ & 0.280 & $0.021^{*}$ & 0.046 & 0.604 \\
\hline $\mathrm{HC}(\mathrm{cm})$ & 0.093 & 0.126 & 0.123 & 0.485 \\
\hline WHR & 0.158 & $0.047^{*}$ & 0.370 & $0.023^{*}$ \\
\hline BAI & $0.176^{*}$ & $0.045^{*}$ & 0.470 & $0.036^{*}$ \\
\hline FPG (mg/dl) & 0.562 & $0.004 *$ & 0.650 & $0.041^{*}$ \\
\hline $\mathrm{PP}(\mathrm{mg} / \mathrm{dl})$ & 0.402 & $0.038^{*}$ & 0.682 & $0.037^{*}$ \\
\hline HbA1c (\%) & 0.210 & $0.016^{*}$ & 0.201 & $0.026^{*}$ \\
\hline $\mathrm{TC}(\mathrm{mg} / \mathrm{dl})$ & 0.282 & $0.001^{* * *}$ & 0.282 & $0.002 *$ \\
\hline TG (mg/dl) & 0.257 & $0.01 *$ & 0.265 & $0.01 *$ \\
\hline HDL (mg/dl) & -0.380 & $0.013^{*}$ & -0.284 & $0.018^{*}$ \\
\hline LDL (mg/dl) & 0.046 & 0.604 & 0.038 & 0.678 \\
\hline VLDL (mg/dl) & 0.112 & 0.206 & 0.252 & 0.104 \\
\hline WBC count (cells/cumm) & 0.198 & $0.024 *$ & 0.182 & $0.023^{*}$ \\
\hline hs-CRP (pg/mL) & 0.174 & $0.048^{*}$ & 0.156 & $0.044^{*}$ \\
\hline
\end{tabular}

Abbreviation: T2DM: type 2 diabetes mellitus; BMI: body mass index; BP: blood pressure; WC: waist circumference; HC; hip circumference; WHR: Waist to hip ratio; BAI: boy adiposity index; FPG: fasting plasma glucose; PP: postprandial glucose; HbA1c: glycated haemoglobin; TC: total cholesterol; TG: triglycerides; HDL: high density lipoprotein; LDL: low density lipoprotein; VLDL: very low density lipoprotein; WBC: white blood cell; hs-CRP: high-sensitivity C-Reactive Protein.

r, Correlation coefficient.

*, Statistically significant correlation $(\mathrm{p}<0.05)$.

Partial correlations; Adjustment for age, sex BMI, weight, \& duration of diabetes.

metabolism; FPG, PP and HbA1c. These findings suggest that obesity and uncontrolled glucose may have a cumulative effect on the serum periostin levels. The outcomes of this study are also support by a recent study which states that T2DM obese patients had the highest levels of plasma periostin and it was positively correlated with BMI, WC, and WHR. ${ }^{11}$ Additionally, the study implies that insulin resistance may be documented as the quite feature of obesity and T2DM, both of which are related to systemic inflammation. ${ }^{14}$ In line with the evidence, our study also found that overweight and obese T2DM patients had higher mean of
Table 5

Multiple regression analysis for serum periostin and biochemical parameters and inflammatory biomarker for T2DM patients.

\begin{tabular}{|c|c|c|c|c|c|}
\hline \multirow[b]{2}{*}{ Variables } & \multicolumn{2}{|c|}{$\begin{array}{l}\text { Unstandardized } \\
\text { Coefficients }\end{array}$} & \multirow{2}{*}{$\begin{array}{l}\text { Standardized } \\
\text { Coefficients } \\
\beta\end{array}$} & \multirow[b]{2}{*}{$P$ value } & \multirow[b]{2}{*}{$\begin{array}{l}\text { Model } \\
\text { Summary } \\
\text { Statistics }\end{array}$} \\
\hline & B & SE & & & \\
\hline $\begin{array}{c}\text { BMI (kg/ } \\
\text { m2) }\end{array}$ & 0.754 & 0.316 & 0.286 & $0.018^{*}$ & $\begin{array}{l}\mathrm{R}=0.529 \\
\mathrm{R}^{2}=0.280\end{array}$ \\
\hline WC (cm) & 0.034 & 0.151 & 0.028 & 0.823 & Adjusted $\mathrm{R}^{2}=$ \\
\hline $\mathrm{HC}(\mathrm{cm})$ & 0.165 & 0.234 & 0.155 & 0.483 & $0.186 \mathrm{df}=15$ \\
\hline BAI & 0.194 & 0.354 & 0.109 & 0.584 & $\mathrm{~F}=2.959$ \\
\hline FPG (mg/dl) & 0.048 & 0.031 & 0.228 & 0.130 & $\mathrm{P}=0.001$ \\
\hline HbA1c (\%) & 1.516 & 0.565 & 0.278 & $0.008^{*}$ & \\
\hline $\mathrm{TC}(\mathrm{mg} / \mathrm{dl})$ & 0.112 & 0.033 & 0.311 & $0.001^{*}$ & \\
\hline $\mathrm{TG}(\mathrm{mg} / \mathrm{dl})$ & 0.311 & 0.236 & 0.144 & $0.040^{*}$ & \\
\hline $\begin{array}{l}\mathrm{HDL}(\mathrm{mg} / \\
\mathrm{dl})\end{array}$ & -0.210 & 0.131 & -0.155 & $0.012^{*}$ & \\
\hline LDL (mg/dl) & 0.046 & 0.040 & 0.107 & 0.243 & \\
\hline $\begin{array}{l}\text { VLDL (mg/ } \\
\text { dl) }\end{array}$ & 0.250 & 0.190 & 0.295 & 0.191 & \\
\hline $\begin{array}{l}\text { WBC count } \\
\text { (cells/ } \\
\text { cumm) }\end{array}$ & 0.001 & 0.001 & 0.177 & $0.042^{*}$ & \\
\hline $\begin{array}{l}\text { hs-CRP (pg/ } \\
\text { mL) }\end{array}$ & 0.004 & 0.004 & 0.179 & $0.049^{*}$ & \\
\hline
\end{tabular}

Abbreviation: T2DM: type 2 diabetes mellitus; BMI: body mass index; BP: blood pressure; WC: waist circumference; HC; hip circumference; BAI: boy adiposity index; FPG: fasting plasma glucose; HbA1c: glycated haemoglobin; TC: total cholesterol; TG: triglycerides; HDL: high density lipoprotein; LDL: low density lipoprotein; VLDL: very low-density lipoprotein; WBC: white blood cell; hs-CRP: high-sensitivity C-Reactive Protein.

* Statistically significant $(\mathrm{p}<0.05)$.

$\beta$ coefficient.

$\mathrm{R}=$ multiple correlation coefficient.

$\mathrm{R}^{2}=$ coefficient of determination.

Dependent variable: periostin.

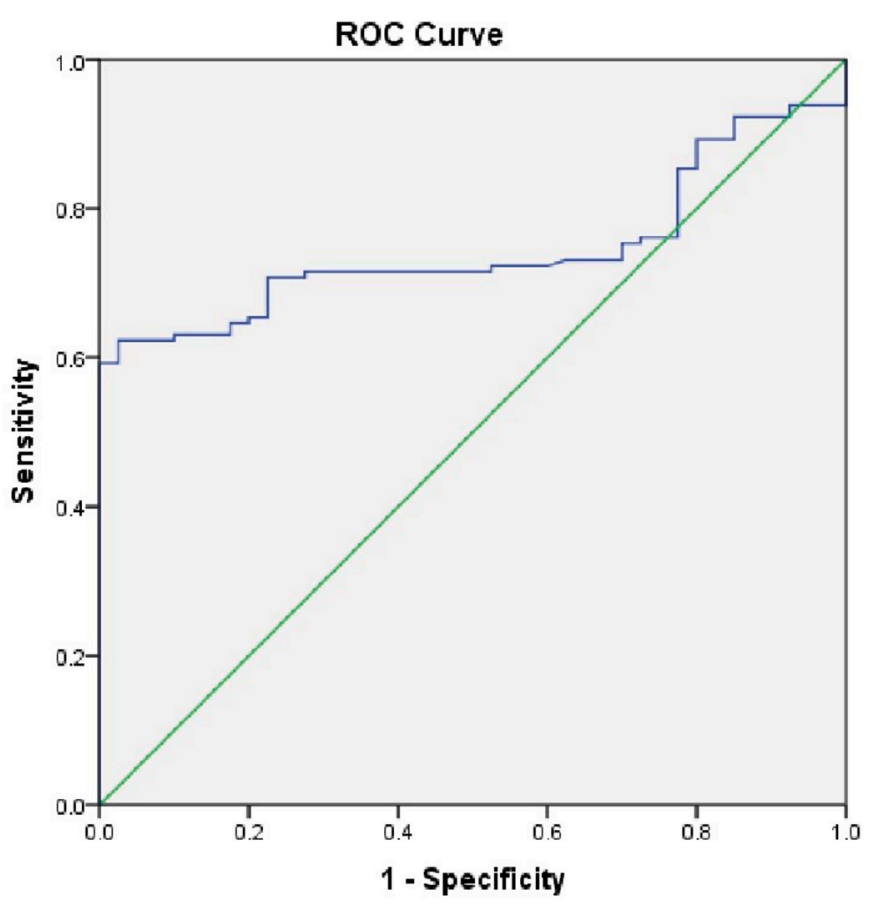

Fig. 3. ROC analysis of serum periostin levels in T2DM. 
inflammatory markers such as WBC count and hs-CRP as compared to normal weight T2DM, and these parameters are significantly correlated with serum periostin levels. A previous study has also shown that periostin plays critical role regulating various inflammatory microenvironments including atherosclerosis, and hepatic inflammation due to its effect on sustaining or amplifying the inflammatory responses in these pathological contexts. ${ }^{36}$ Collective evidence from the study considering serum periostin levels related to inflammation and closely associated with lipid metabolism, obesity, and diabetes, may indicate the strong association between periostin, inflammation, and metabolic disorders. ${ }^{37}$

Our results revealed that periodic estimation of the circulating serum periostin could be a biomarker to predict the risk of developing cardiovascular complications in patients with T2DM.

In spite of several strengths there are few limitations which need to be discussed in the presented study. First, our study is cross-sectional study without follow up, and a large-scale prospective cohort study is needed to confirm the usefulness of circulating periostin as a predictive biomarker of CVD risk in patients with T2DM. Secondly, the impact of antidiabetic and other medication on serum periostin level was not investigated.

\section{Conclusion}

In conclusion, the present study found that serum periostin levels were significantly higher in ACS patients and T2DM and obese subjects and were strongly associated with TG metabolism, chronic inflammation, and body fat parameters. Periostin may act as a scaffold and remodeling protein in inflammatory responses, and obesity, which may predict the risk of CVD in patients with T2DM. Therefore, our results revealed that periodic estimation of the circulating serum periostin could be a biomarker to predict the risk of developing cardiovascular complications in patients with T2DM.

Moreover, further study with large sample size with long-term follow-up are needed to explore the relationship between periostin, insulin resistance and inflammation, and robust the present findings.

\section{Funding}

None.

\section{Ethical approval}

This protocol was reviewed and approved by Jamia Hamdard Institutional Ethics Committee (JHIEC), New Delhi, India.

\section{Declaration of competing interest}

There is no known conflict of interest associated with this publication.

\section{Acknowledgements}

First author (Md Azharuddin) is thankful to Sun Pharmaceuticals, India, for providing assistantship for this project under the joint collaboration for the Ph.D. programme with Jamia Hamdard, New Delhi, India.

\section{References}

1 IDF. Diabetes and cardiovascular disease. 2020. https://www.idf. org/our-activities/care-prevention/cardiovascular-disease.html\#introarea; 2020. Accessed October 27, 2020. Accessed.

2 Fisher M. Diabetes and atherogenesis. Heart. 2004:90(3):336-340.

3 Mohanty L, Sahoo D, Meher D, Sahoo P. Prevalence of diabetes in patients with myocardial infarction: a study in a tertiary care centre. Int J Adv Med. 2016;3: 842-846.
4 De Luca C, Olefsky JM. Inflammation and insulin resistance. FEBS Lett. 2008;582(1): 97-105.

5 Lu Y, Liu X, Jiao Y, et al. Periostin promotes liver steatosis and hypertriglyceridemia through downregulation of PPAR $\alpha$. J Clin Invest. 2014;124(8):3501-3513.

6 Hirosumi J, Tuncman G, Chang L, et al. A central role for JNK in obesity and insulin resistance. Nature. 2002;420(6913):333-336.

7 Khan RA, Kapur P, Jain A, Farah F, Bhandari U. Effect of orlistat on periostin, adiponectin, inflammatory markers and ultrasound grades of fatty liver in obese NAFLD patients. Therapeut Clin Risk Manag. 2017;13:139.

8 Conway SJ, Izuhara K, Kudo Y, et al. The role of periostin in tissue remodeling across health and disease. Cell Mol Life Sci. 2014;71(7):1279-1288.

9 Snider P, Standley KN, Wang J, Azhar M, Doetschman T, Conway SJ. Origin of cardiac fibroblasts and the role of periostin. Circ Res. 2009;105(10):934-947.

10 Azharuddin M, Adil M, Ghosh P, Kapur P, Sharma M. Periostin as a novel biomarker of cardiovascular disease: a systematic evidence landscape of preclinical and clinical studies. J Evid Base Med. 2019;12(4):325-336.

11 Luo Y, Qu H, Wang H, et al. Plasma periostin levels are increased in Chinese subjects with obesity and type 2 diabetes and are positively correlated with glucose and lipid parameters. Mediat Inflamm. 2016;2016.

12 Cohen JC, Horton JD, Hobbs HH. Human fatty liver disease: old questions and new insights. Science. 2011;332(6037):1519-1523.

13 Michelotti GA, Machado MV, Diehl AM. NAFLD, NASH and liver cancer. Nat Rev Gastroenterol Hepatol. 2013;10(11):656-665.

14 Hotamisligil GS. Inflammation and metabolic disorders. Nature. 2006;444(7121): $860-867$.

15 Donath MY. Targeting inflammation in the treatment of type 2 diabetes: time to start. Nat Rev Drug Discov. 2014;13(6):465-476.

16 Guan J, Liu W-Q, Xing M-Q, et al. Elevated expression of periostin in diabetic cardiomyopathy and the effect of valsartan. BMC Cardiovasc Disord. 2015;15(1):1-8.

17 Litvin J, Blagg A, Mu A, et al. Periostin and periostin-like factor in the human heart: possible therapeutic targets. Cardiovasc Pathol. 2006;15(1):24-32.

18 Cheng E, Souza RF, Spechler SJ. Tissue remodeling in eosinophilic esophagitis. Am J Physiol Gastrointest Liver Physiol. 2012;303(11):G1175-G1187.

19 Laury AM, Hilgarth R, Nusrat A, Wise SK. Periostin and receptor activator of nuclear factor к-B ligand expression in allergic fungal rhinosinusitis. Int Forum Allergy Rhinol. 2014 Sep;4(9):716-724.

20 Association WM. World Medical Association Declaration of Helsinki. Ethical principles for medical research involving human subjects. Bull World Health Organ. 2001;79(4):373.

21 Vandenbroucke JP, Von Elm E, Altman DG, et al. Strengthening the reporting of observational studies in Epidemiology (STROBE): explanation and elaboration. PLOS Med. 2007;4(10):e297.

22 Misra A. Ethnic-specific criteria for classification of body mass index: a perspective for Asian Indians and American Diabetes Association position statement. Diabetes Technol Therapeut. 2015;17(9):667-671.

23 Bergman RN, Stefanovski D, Buchanan TA, et al. A better index of body adiposity. Obesity. 2011;19(5):1083-1089.

24 Cimmino G, S Loffredo F, Morello A, et al. Immune-inflammatory activation in acute coronary syndromes: a look into the heart of unstable coronary plaque. Curr Cardiol Rev. 2017;13(2):110-117.

25 Cheng W, Lan S, Li H, Wan X, Wu M. The correlation between acute coronary syndrome and serum parameters: HMGB1, periostin, PAI-1, SCD163 and MEF2A. Acta Med Mediterr. 2019;35(4):1813-1817.

26 Li M, Chen Y, Zhang Y, Li D, Liu J. Correlation between monocyte chemoattractant protein-1/chemokine (CC motif) ligand 2 and coronary plaque characteristics. Exp Biol Med. 2020;245(15):1335-1343.

27 Davies MJ, Thomas A. Thrombosis and acute coronary-artery lesions in sudden cardiac ischemic death. N Engl J Med. 1984;310(18):1137-1140.

28 Botto N, Sbrana S, Trianni G, et al. An increased platelet-leukocytes interaction at the culprit site of coronary artery occlusion in acute myocardial infarction: a pathogenic role for "no-reflow" phenomenon? Int J Cardiol. 2007:117(1):123-130.

29 Davì G, Patrono C. Platelet activation and atherothrombosis. N Engl J Med. 2007;357 (24):2482-2494.

30 Kaplan ZS, Jackson SP. The role of platelets in atherothrombosis. Hematology 2010. 2011;2011(1):51-61. the American Society of Hematology Education Program Book.

31 Rajkovic N, Zamaklar M, Lalic K, et al. Relationship between obesity, adipocytokines and inflammatory markers in type 2 diabetes: relevance for cardiovascular risk prevention. Int J Environ Res Publ Health. 2014;11(4):4049-4065.

32 Twig G, Afek A, Shamiss A, et al. White blood cell count and the risk for coronary artery disease in young adults. PloS One. 2012;7(10), e47183.

33 Wang Z, Nakayama T. Inflammation, a link between obesity and cardiovascular disease. Mediat Inflamm. 2010;2010.

34 Ebrahimi M, Heidari-Bakavoli AR, Shoeibi S, et al. Association of serum hs-CRP levels with the presence of obesity, diabetes mellitus, and other cardiovascular risk factors. J Clin Lab Anal. 2016;30(5):672-676.

35 Kamath DY, Xavier D, Sigamani A, Pais P. High sensitivity C-reactive protein (hsCRP) \& cardiovascular disease: an Indian perspective. Indian J Med Res. 2015;142(3):261.

36 Liu AY, Zheng H, Ouyang G. Periostin, a multifunctional matricellular protein in inflammatory and tumor microenvironments. Matrix Biol. 2014:37:150-156.

37 Bradbury MW. Lipid metabolism and liver inflammation. I. Hepatic fatty acid uptake: possible role in steatosis. Am J Physiol Gastrointest Liver Physiol. 2006;290(2): G194-G198. 